\title{
Triangulasi Konsep Kerja Sama Pemerintah dengan Badan Usaha (KPBU) untuk Menjembatani Kesenjangan Keterampilan di Masyarakat Ekonomi ASEAN ${ }^{1}$
}

\author{
Aloysius Efraim Leonard, Richard Theo Parulian dan Ruth Latreia T. Saphira \\ Universitas Katolik Parahyangan \\ aloysiusefraim@gmail.com, richardtheopt@yahoo.com, ruthlatreia@gmail.com
}

\begin{abstract}
ABSTRAK
Implementasi konsep Masyarakat Ekonomi ASEAN (MEA) telah dimulai pada tahun 2015 silam. Kehadiran MEA sebagai bentuk integrasi regional bertujuan untuk meningkatkan daya saing kawasan Asia Tenggara dalam konstelasi perekonomian global. Pemberlakuan MEA ditandai dengan penerapan sejumlah hukum internasional terhadap negara-negara anggota, seperti penurunan tarif barang dan peningkatan fasilitas serta kualitas perdagangan dan bisnis. Dalam menganalisis, penulis terfokus kepada sektor perdagangan jasa dengan sub-sektor bidang Science, Technology, Engineering, and Mathematics (STEM). Hal ini didasarkan kepada kondisi geostrategi ASEAN terkait demografi kependudukan yang berpotensi menguntungkan, namun terhambat oleh kesenjangan keterampilan para pekerja antarnegara anggota ASEAN dalam penguasaan bidang teknologi dan mesin. Tanpa penanggulangan yang sesuai, MEA dikhawatirkan dapat menjadi faktor penunjang kegagalan pencapain moto One Vision, One Identity, One Community itu sendiri. Oleh sebab itu, penulis menganalisis efektivitas salah satu bentuk kerja sama yang diatur dalam kerangka ASEAN, yakni Public Private Partnership (PPP) atau Kerja Sama Pemerintah dengan Badan Usaha (KPBU). Melalui studi pustaka yang dikaji secara kualitatif, penulis menemukan bahwa dengan menambahkan organisasi regional ASEAN kedalam skema triangulasi stakeholder KPBU, strategi pemenuhan visi MEA dapat dilakukan secara lebih efektif dan efisien. Pada akhirnya, tulisan ini diharapkan dapat diadaptasi dan menjadi panduan bagi pengembangan bentuk kerja sama lainnya.
\end{abstract}

Kata Kunci: MEA, Kesenjangan Keterampilan, Perdagangan Jasa, STEM, Triangulasi KPBU.

\section{Latar Belakang Masalah}

One Vision, One Identity, One Community (Satu Visi, Satu Identitas dan Satu Komunitas) merupakan sebuah moto yang di promosikan oleh ASEAN (Association of South East Asian Nations) dengan tujuan untuk menyatukan negara-negara di Asia Tenggara melalui sebuah kepemilikan akan visi dan identitas yang sama, serta membentuk suatu komunitas bersama. Penyusunan semboyan ini didasarkan kepada Deklarasi ASEAN, yang menyatakan bahwa salah satu tujuan organisasi intra-pemerintah ini adalah untuk mempercepat pertumbuhan ekonomi, kemajuan sosial, dan perkembangan budaya melalui suatu kerja sama yang berasaskan kesetaraan dan kemitraan untuk memperkuat fondasi komunitas bangsa

${ }^{1}$ Tulisan ini merupakan pelengkapan dan perbaikan dari karya tulis yang dilombakan pada NAFIGATION (National Infographic and Essay Competition) yang dilakukan di Yogyakarta oleh penulis. Tulisan ini meraih penghargaan $2^{\text {nd }}$ Best Paper dalam perlombaan tersebut. 
Asia Tenggara yang makmur dan tenteram. ${ }^{2}$ Pada tahun 2007, ASEAN melalui Deklarasi Cebu menegaskan percepatan target implementasi ASEAN Community (Komunitas ASEAN) lima tahun lebih awal dari tahun 2020 menjadi tahun $2015 .{ }^{3}$ Komunitas ASEAN itu sendiri terbagi menjadi tiga bentuk: (1) Masyarakat Politik-Keamanan ASEAN (ASEAN Political-Security Community), (2) Masyarakat Ekonomi ASEAN (ASEAN Economic Community), dan (3) Masyarakat Sosial Budaya ASEAN (ASEAN Socio-Cultural Community). Dari ketiga klasifikasi tersebut, penulis akan membahas lebih lanjut mengenai Masyarakat Ekonomi ASEAN (selanjutnya disebut sebagai MEA), sebuah konsep yang memproyeksikan ASEAN menjadi penguasa perekonomian global.

Berdirinya MEA didukung oleh dua buah cetak biru (blueprint), yakni untuk tahun 2015 dan 2025 yang saling melengkapi. Cetak Biru MEA 2015 menyebutkan adanya empat pilar yang menjadi fondasi komunitas tersebut, yaitu: (1) Pasar dan basis produksi tunggal, (2) Kawasan ekonomi berdaya saing tinggi, (3) Kawasan dengan pembangunan ekonomi yang merata dan berkeadilan, dan (4) Kawasan yang terintegrasi dengan ekonomi global. ${ }^{4}$ Di sisi lain, terdapat Cetak Biru MEA 2025 yang memiliki lima karakteristik, yaitu: (1) Ekonomi yang terpadu dan terintegrasi penuh, (2) ASEAN yang berdaya saing, (3) Inovatif dan dinamis, (4) Peningkatan konektivitas dan kerja sama sektoral, (4) ASEAN yang berorientasi pada masyarakat, dan (5) ASEAN yang global. ${ }^{5}$ Selain untuk melengkapi Cetak Biru MEA 2015, lima karakteristik tersebut dibentuk untuk mencapai seluruh visi Integrasi Ekonomi ASEAN, salah satunya adalah dalam bidang perdagangan jasa.

Pada dasarnya, ASEAN menargetkan agar perdagangan jasa dapat semakin terintegrasi di dalam pasar global dan meningkatkan daya saing pekerja ASEAN. ${ }^{6}$ Selain tercantum dalam Cetak Biru MEA 2015 dan 2025, perdagangan jasa juga dimuat dalam Kerangka Persetujuan Jasa ASEAN (ASEAN Framework Agreement on Services) atau AFAS. AFAS bertujuan untuk meningkatkan kerja sama antarnegara anggota, mengurangi batasan dalam perdagangan jasa, dan untuk meliberalisasikan perdagangan jasa berdasarkan Perjanjian Umum tentang Perdagangan Jasa (General Agreement on Trade in Services) atau GATS. ${ }^{7}$ Melalui AFAS, negara anggota ASEAN sepakat untuk mengakui tingkat pendidikan atau pengalaman, pemenuhan syarat kualifikasi, dan lisensi atau sertifikasi yang diraih oleh seseorang dari negara anggota ASEAN lainnya. ${ }^{8}$

Namun pada kenyataannya, setelah empat tahun pelaksanaan MEA, masih terdapat perbedaan dan kesenjangan antarnegara anggota ASEAN. Berdasarkan jumlah Produk Domestik Bruto (PDB), negara-negara ASEAN sering dikategorikan menjadi dua kelompok: ASEAN-6 (Singapura, Malaysia, Indonesia, Brunei Darussalam, Thailand, dan Filipina) serta CLMV (Kamboja, Laos, Myanmar, dan

\footnotetext{
${ }^{2}$ ASEAN, “About ASEAN," https://asean.org/asean/about-asean/ (Diakses 23 Juli 2019).

3 Ibid.

4 Kementerian Luar Negeri Republik Indonesia, "Masyarakat Ekonomi ASEAN (MEA)," 1 Agustus 2019, https://kemlu.go.id/portal/id/read/113/halaman_list_lainnya/masyarakat-ekonomi-asean-mea, (Diakses 23 Juli 2019).

5 Ibid

${ }^{6}$ ASEAN Economic Community Blueprint 2025.

7 ASEAN, “ASEAN Framework Agreement on Services," https://asean.org/?static_post=asean-framework-agreement-onservices (Diakses 23 Juli 2019).

8 Ibid
} 
Vietnam). Selain itu, secara domestik, pasar tenaga kerja negara-negara ASEAN masih mengalami masalah kesenjangan keterampilan. Sebuah penelitian oleh J.P. Morgan dan Singapore Management University (SMU) menunjukkan bahwa bahkan ASEAN-5 (Indonesia, Singapura, Malaysia, Thailand dan Filipina) mengalami kekurangan tenaga kerja terampil yang siap untuk keperluan industri. ${ }^{9}$ Sebuah laporan dari International Labor Organization atau ILO menunjukkan bahwa keterampilan yang dimiliki tenaga kerja ASEAN tidak sesuai dengan kebutuhan industri, terutama industri yang dapat memberikan pekerjaan berkualitas tinggi. ${ }^{10}$ Selain itu, dilaporkan juga bahwa mayoritas tenaga kerja ASEAN kekurangan kemampuan dalam soft skills seperti manajemen waktu, penyelesaian masalah dan komunikasi. ${ }^{11}$

Dengan adanya perkembangan teknologi pula, keterampilan - keterampilan yang dibutuhkan oleh industri yang ada di ASEAN terus berubah. Teknologi disruptif seperti robot dan mesin diprediksi akan mengganti pekerja ASEAN, sehingga tenaga kerja diharapkan untuk menguasai keterampilan keterampilan yang lain, yang bahkan mungkin untuk sekarang belum dianggap penting. ${ }^{12}$ Hal ini menyebabkan pembelajaran terhadap teknik, kesehatan dan ilmu alam menjadi sangat penting. ${ }^{13}$

Adanya kesenjangan keterampilan akan sangat mempengaruhi implementasi MEA. Perbedaan dan kesenjangan keterampilan antarnegara anggota ASEAN akan menyulitkan integrasi pasar tenaga kerja dan juga perdagangan jasa di kawasan ini sendiri. Selain itu, menjadikan ASEAN sebuah kawasan yang kompetitif dan berdaya saing akan sulit tanpa adanya tenaga kerja yang terampil dan sesuai dengan kebutuhan industri. Sehingga, perlu ditemukan sebuah solusi untuk menyelesaikan masalah ini, yang tidak hanya melibatkan pemerintah domestik namun juga ASEAN sendiri sebagai institusi dan sektor swasta.

Berdasarkan pemaparan yang telah disampaikan, peneliti hendak merumuskan problematika utama yang akan dijawab dalam karya tulis ini. Permasalahan tersebut dirangkum dan diwujudkan menjadi sebuah pertanyaan penelitian, yakni "Bagaimana posisi ASEAN dalam triangulasi konsep

Kerja Sama Pemerintah dengan Badan Usaha (KPBU) dapat menjembatani kesenjangan keterampilan di MEA?"

\section{Integrasi Ekonomi di ASEAN}

Konsep integrasi ekonomi telah mendorong terjadinya liberalisasi ekonomi dengan memfasilitasi arus perdagangan bebas jasa, investasi bahkan pergerakan manusia yang melintasi batas

\footnotetext{
${ }^{9}$ Phidel Vineles, “Enhancing ASEAN's Competitiveness: The Skills Challenge,” RSIS, 12 Januari 2018, https://www.rsis.edu.sg/wp-content/uploads/2018/01/CO18006.pdf (Diakses 29 Juli 2019).

${ }^{10}$ Monika Aring, "ASEAN Economic Community 2015: Enhancing Competitiveness and Employability Through Skill Development," International Labour Organization, February 2015, https://www.ilo.org/wcmsp5/groups/public/---asia/---robangkok/documents/publication/wcms_344796.pdf (Diakses 29 Juli 2019).

${ }^{11}$ Ibid

12 "Human Capital Outlook: Association of Southeast Asian Nations (ASEAN)," World Economic Forum, http://www3.weforum.org/docs/WEF_ASEAN_HumanCapitalOutlook.pdf, hlm. 6, (Diakses 30 Juli 2019).

${ }^{13}$ Ibid., 7.
} 
negara. ${ }^{14}$ Integrasi ekonomi adalah upaya dan proses menghilangkan batasan-batasan yang menghambat perdagangan antar negara seperti perbedaan regulasi, dan harga. Dalam mencapai hal tersebut, diperlukan komunitas ekonomi yang memfasilitasi pembentukan perjanjian tersebut. ASEAN, misalnya, memegang peran yang signifikan dalam pertumbuhan ekonomi regional Asia Timur. ASEAN telah mendirikan ASEAN Economic Community dan beberapa perjanjian Free Trade Agreements (FTA) yang mendorong implementasi integrasi ekonomi dalam wilayah Asia. Menurut Mari Pangestu dan Shiro Armstrong dalam jurnalnya yang berjudul "Asian Economic Integration: The State of Play," Asia Timur sedang mengalami pertumbuhan ekonomi, perdagangan, dan investasi yang sangat tinggi dibandingkan dengan wilayah regional lainnya. ${ }^{15} \mathrm{Hal}$ ini disebabkan oleh berkembangnya aktor-aktor yang mementingkan integrasi ekonomi.

Integrasi ekonomi yang berbentuk FTA ini telah berkembang pesat dalam meningkatkan pertumbuhan dan aktivitas ekonomi di wilayah Asia Timur. Pada akhir Februari 2016, Asian Development Bank (ADB) melaporkan bahwa terdapat 133 FTA di Asia Timur. ${ }^{16}$ ASEAN telah menjadi pelopor dalam perjanjian perdagangan regional di Asia Timur dengan membangun FTA serta ASEAN+1 FTA. Terjadinya krisis finansial pada tahun 1997 menjadi faktor pendorong dalam mempromosikan kerja sama regional dalam Asia Timur. Terbentuknya kerja sama ASEAN+3 adalah respon langsung terhadap krisis $1997 .{ }^{17}$

Dengan adanya perbedaan struktur industri, struktur pengembangan, status perdagangan, serta pembangunan ekonomi, negara-negara Asia merasa pentingnya untuk memiliki beberapa strategi FTA untuk memaksimalkan kepentingan mereka yang berbeda-beda. ASEAN centrality membantu negaranegara Asia untuk mencapai kemaksimalan keuntungan dengan mendirikan ASEAN sebuah komunitas ekonomi. ASEAN telah mengembangkan beberapa FTA dengan negara lain misalnya, ASEAN+1. ASEAN+1 adalah bentuk kerja sama China dan ASEAN, upaya ini dilakukan oleh ASEAN karena kondisi ekonomi Tiongkok dan produktivitas wilayah Asia Timur sangat terintegrasi satu dengan yang lain. ${ }^{18}$ Dengan adanya FTA yang berdasarkan konsep integrasi ekonomi, kondisi ekonomi di wilayah Asia Tenggara mengalami kemajuan yang signifikan dikarenakan aktivitas perdagangan antarnegara di wilayah tersebut meningkat.

\section{Gambaran Tenaga Kerja ASEAN}

\footnotetext{
${ }^{14}$ Mari Pangestu dan Shiro Armstrong, "Asian Economic Integration: The State of Play," dalam Asian Economic Integration in an Era of Global Uncertainty, Shiro Amstrong dan Tom Westland (ed.), hlm. 18, (Australia: ANU Press, 2018).

${ }^{15}$ Ibid., 15

${ }^{16}$ Shen Minghui, "Evaluation of Regional Economic Integration in East Asia," dalam Asian Economic Integration in an Era of Global Uncertainty, Shiro Amstrong dan Tom Westland (ed.), hlm. 263, (Australia: ANU Press, 2018).

${ }^{17}$ Ibid., 260.

${ }^{18}$ Ibid., 256.
} 
Untuk mendapatkan hasil analisis yang komprehensif, penulis melakukan beberapa observasi melalui laporan - laporan yang dibuat oleh berbagai pihak yang kredibel. Temuan - temuan tersebut akan dipaparkan dalam bentuk tabel yang akan dijelaskan.

\section{Tabel 1.1 Prospek Pekerjaan oleh Pekerjaan Utama Keluarga}

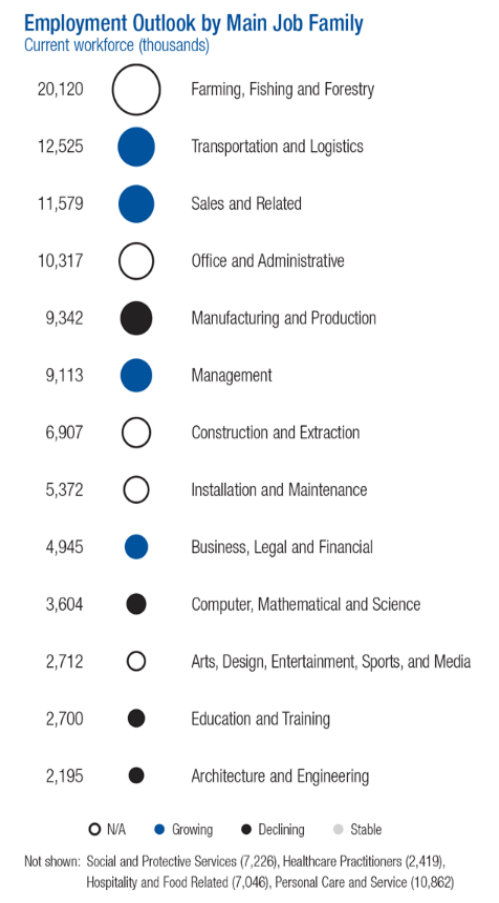

Sumber: The Future of Jobs World Economic Forum 2016

Berdasarkan laporan World Economic Forum (WEF) tahun 2016, bertajuk "Human Capital Outlook: Association of Southeast Asian Nations (ASEAN)," hampir 40\% $(20,120,000)$ dari tenaga kerja di ASEAN berada di sektor agrikultur, $41 \%$ berada di sektor jasa, dan $19 \%$ berada di sektor industri. Selain itu, tabel di atas juga menunjukkan bahwa walaupun mayoritas tenaga kerja ASEAN bekerja di bidang agrikultur, bidang lainnya seperti jasa transportasi, sales, manajemen dan bisnis sedang berkembang, sementara manufaktur, edukasi dan arsitektur semakin berkurang.

\section{Tabel 1.2 Tren Industri yang Berpengaruh}
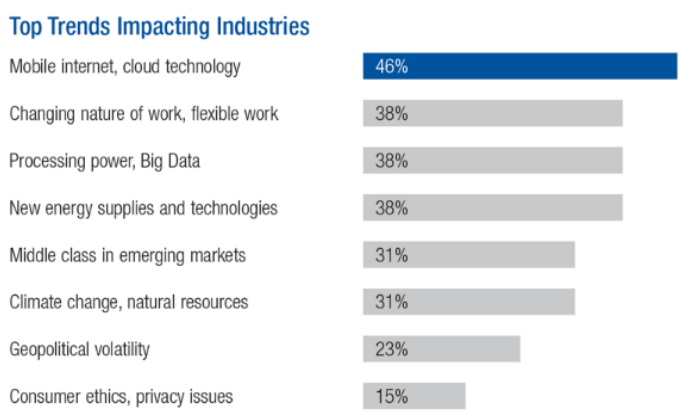

Sumber: The Future of Jobs, World Economic Forum 2016 
Namun, World Economic Forum di saat yang bersamaan menunjukkan bahwa sektor yang sedang berdampak terhadap ekonomi ASEAN sudah bukan lagi agrikultur, namun sektor industri. Sektor industri ini termasuk pekerjaan yang berhubungan dengan STEM, karena membutuhkan kemampuan seperti teknologi informasi, pengolahan energi dan lainnya.

Tabel 1.3 Kesesuaian Keterampilan Lulusan Perguruan Tinggi dengan Kebutuhan Perusahaan Sumber: Asia Pacific Working Paper, International Labour Organization 2014

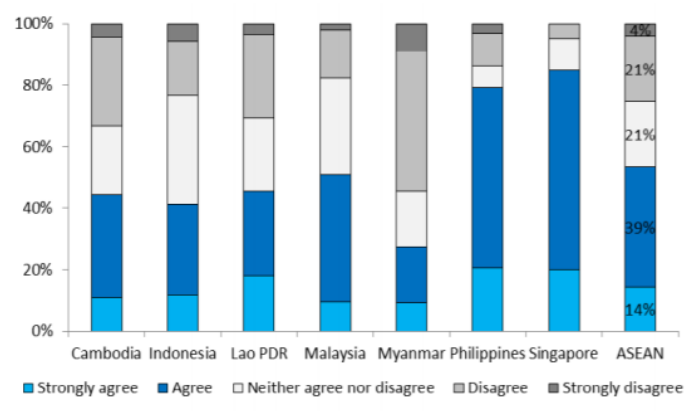

Dengan keadaan yang seperti ini, ketika apa yang ditawarkan dan apa yang diminta dalam pekerjaan tidak sesuai, ILO melakukan survei kepada pengusaha dan pekerja ASEAN dalam hal keterampilan dan daya saing. Secara umum dalam lingkup regional / ASEAN, para pekerja merasa bahwa keterampilan yang mereka pelajari dalam universitas sudah cukup sesuai dengan permintaan dari perusahaan-perusahaan. Namun secara domestik, hasil setiap negara beragam. Di Myanmar, banyak lulusan perguruan tinggi yang menganggap bahwa apa yang mereka pelajari tidak sesuai dengan apa yang dibutuhkan oleh industri di negara mereka. Sementara itu, di negara lain seperti Filipina dan Singapura, sebagian besar beranggapan bahwa apa yang mereka pelajari sudah sesuai.

Dari hasil di atas, dapat disimpulkan bahwa terdapat jarak antara keterampilan dan kemampuan yang dimiliki oleh tenaga kerja ASEAN dengan kebutuhan perusahaan yang ada. Selain itu, terlihat juga bahwa para pelajar di ASEAN tidak selamanya setuju bahwa apa yang mereka pelajari di perguruan tinggi sesuai dengan kebutuhan perusahaan yang akan mempekerjakan mereka. Maka dari itu, dibutuhkan sebuah cara untuk menjembatani permasalahan ini, yang dapat berbentuk KPBU atau public private partnership.

\section{Triangulasi KPBU untuk Mengurangi Kesenjangan Keterampilan}

Public private partnership, atau Kerja Sama Pemerintah dan Badan Usaha (KPBU) adalah sebuah kontrak jangka panjang antara pemerintah dan sektor swasta. Sektor swasta dalam hal ini berarti lingkungan suatu usaha yang bukan dimiliki oleh pemerintah. Di dalam tulisan ini, pemerintah yang dimaksud adalah pemerintah domestik negara - negara anggota ASEAN. Selama periode penyusunan dan pengembangan konsep KPBU di masing-masing negara ASEAN, salah satu tren utama KPBU 
ASEAN adalah penghapusan segala hambatan hukum dalam mengimplementasi KPBU. Hal ini dilakukan melalui: (1) Reformasi undang-undang investasi asing, (2) Amandemen undang-undang prosedur pengadaan atau undang-undang yang memungkinkan terciptanya KPBU, (3) pengembangan kriteria untuk aktualisasi struktur KPBU, dan (4) pengembangan aturan pengadaan konsep kerja sama yang telah diperbaharui. ${ }^{19}$

Pemerintah domestik belakangan ini banyak melakukan KPBU dikarenakan pendanaan untuk fasilitas publik terbatas. Kondisi tersebut menyebabkan alokasi dana bagi pembangunan infrastruktur harus berkompetisi dengan prioritas pemerintah lainnya, sehingga pemerintah bekerja sama dengan sektor swasta untuk mengisi kekurangan dana tersebut. KPBU juga melatih dan meningkatkan kualitas sektor swasta untuk menghasilkan produk inovatif, dan sekaligus memunculkan laba. Tantangan dalam mengimplementasikan KPBU dalam ranah yang besar adalah sistemnya yang kompleks, yakni membutuhkan pengetahuan yang spesifik mengenai struktur pendanaan, risiko alokasi, manajemen kontrak, dan resolusi konflik. KPBU dianggap sebagai variabel pelengkap bagi pendanaan fasilitas publik yang belum memadai. KPBU mewajibkan adanya dukungan dari lingkungan berbisnis melalui keputusan untuk berinvestasi.

KPBU dapat bersifat 2 arah, yaitu antara pemerintah dan sektor swasta yang terlibat atau 3 arah (triangular), yaitu antara pemerintah, sektor swasta, dan pihak ketiga. Triangulasi KPBU yang melibatkan ASEAN akan mendorong pemerintah domestik, sektor swasta, dan ASEAN sebagai institusi untuk bekerja sama dalam infrastruktur di sektor ekonomi. PPP Knowledge Lab menjelaskan bahwa dalam KPBU, sektor swasta bertanggung jawab untuk mengelola proyek yang diberikan oleh pemerintah. Proyek-proyek ini berbentuk fasilitas publik, dan lainnya. ${ }^{20}$ Dengan terlibatnya ASEAN dalam KBPU, KPBU dapat memperluas cakupannya menjadi kerjasama regional antarnegara ASEAN.

Pada akhir tahun 2014, ASEAN mengeluarkan panduan kerjasama KPBU berjudul "ASEAN PPP Guidelines". Panduan ini ditujukan untuk membantu para pemerintah negara ASEAN untuk menghasilkan prosedur terbaik dalam mengimplementasikan proyek KPBU. Dalam membentuk kerangka KPBU, ASEAN memiliki 4 (empat) prinsip. Pertama, prinsip membahas mengenai persyaratan untuk penetapan kebijakan dan kerangka kerja sebuah organisasi yang kuat dalam pemerintahan dan lingkungan yang kondusif untuk mendukung partisipasi sektor swasta. Kedua, prinsip berhubungan dengan proses dari KPBU (pemilihan, pengembangan dan implementasi) dan diikuti oleh prinsip selanjutnya. Ketiga, prinsip ini memastikan adanya keterjangkauan dan transparansi dari anggaran kerja sama KPBU. Terakhir, prinsip membahas mengenai konsep KPBU transnasional untuk pembangunan infrastruktur konektivitas. ${ }^{21}$

\footnotetext{
19 "National Public-Private Partnership Frameworks in ASEAN Member Countries," ERIA, http://www.eria.org/PPP\%20in\%20ASEAN_Full\%20Report_2015.pdf (Diakses 30 Juli 2019).

20 "What are Public Private Partnerships?" World Bank Group, 2 Juni 2018, https://ppp.worldbank.org/public-privatepartnership/overview/what-are-public-private-partnerships (Diakses 25 Juli 2019).

21 "ASEAN PUBLIC-PRIVATE PARTNERSHIP REGIONAL FRAMEWORK FOR TECHNOLOGY DEVELOPMENT IN THE FOOD, AGRICULTURE AND FORESTRY (FAF) SECTORS,” ASEAN, https://asean.org/storage/2012/05/18.ASEAN-PPP-Framework-FAF.pdf (Diakses 30 Juli 2019).
} 
Berdasarkan data "2014-2015 Global Competitiveness Report" oleh WEF, masih terdapat ketimpangan yang besar diantara negara ASEAN itu sendiri, mulai dari Singapura dengan posisi kedua, hingga Myanmar di posisi ke-137 dari 144 negara. ${ }^{22}$ Perbedaan yang dimiliki negara ASEAN ini menyebabkan adaptasi konsep KPBU di ASEAN masih berada dalam tahap transisi. Hal ini berdampak kepada beberapa hal lainnya, seperti rendahnya jumlah negara-negara ASEAN yang terkualifikasi sebagai 'developed', serta rendahnya tingkat kematangan pasar modal yang seharusnya menjadi penyokong bagi aspek pembiayaan KPBU. ${ }^{23}$ Secara spesifik, terdapat 10 tantangan utama bagi negara ASEAN-5:

1. Inability of the educational institutions to meet industry demands (ketidakmampuan institusi ekonomi untuk memenuhi kebutuhan industri);

2. A lack of a comprehensive skills development roadmap to support economic growth (kurangnya peta jalan pengembangan keterampilan untuk mendukung perkembangan ekonomi);

3. Inadequacy in English proficiency and other soft skills (kurangnya kecakapan dalam berbahasa Inggris dan soft skill lainnya);

4. Weakness in STEM and Technical and Vocational Education and Training (TVET) programs (ketidakmampuan dalam bidang STEM dan Edukasi dan Pelatihan Teknis dan Vokasional);

5. Over-reliance on the public sector to meet the skills challenges (ketergantungan yang berlebih terhadap sektor publik untuk memenuhi tantangan keterampilan);

6. Lack of lifelong learning opportunities for mid-level workers (kurangnya kesempatan untuk belajar yang panjang bagi pekerja tingkat menengah);

7. Seriousness of youth unemployment (pengangguran angkatan kerja muda);

8. Skills challenges arising from intra-regional labor flows (tantangan keterampilan dari pekerja intraregional);

9. Skills challenges posed by disruptive technology (tantangan keterampilan dari teknologi), dan;

10. Skills challenges coming from industrial restructuring in China (tantangan keterampilan yang dihasilkan oleh restrukturisasi industri Tiongkok). ${ }^{24}$

Selain itu, negara-negara seperti Kamboja (Cambodia), Laos, Myanmar dan Vietnam (CLMV) merasakan dampak globalisasi yang sangat signifikan. CLMV adalah negara-negara yang sangat

\footnotetext{
${ }^{22}$ Klaus Schwab, “The Global Competitiveness Report 2014-2015,” World Economic Forum, http://www3.weforum.org/docs/WEF_GlobalCompetitivenessReport_2014-15.pdf (Diakses 29 Juli 2019).

${ }_{23}$ Zen F. and M. Regan (eds) (2014), 'Financing ASEAN Connectivity', ERIA Research Project Report No. 15. Jakarta: Economic Research Institute for ASEAN and East Asia. http://www.eria.org/publications/research_project_reports/FY2013/No.15.html (Diakses 29 Juli 2019).

24 “Managing Skills Challenges in ASEAN-5," J.P.Morgan, https://www.jpmorganchase.com/corporate/CorporateResponsibility/document/ASEAN5-executive-summary-final.pdf (Diakses 1 Agustus 2019).
} 
bergantung kepada sektor agrikultur. Namun, dengan globalisasi, beberapa sektor non-agrikultur telah beralih kepada industri. Kontribusi sektor industri semakin hari semakin meningkat dan menjadi ancaman bagi para pekerja dalam sektor agrikultur. Industri telah menggantikan kegiatan pertanian. Dengan ini, pekerja berketerampilan rendah perlu memiliki kesempatan untuk mengembangkan keterampilannya agar dapat menyesuaikan kepada permintaan pasar. Tantangan bagi negara CLMV adalah untuk mempersiapkan para pekerja untuk mendapatkan keterampilan yang lebih tinggi sebelum terlambat. ${ }^{25}$

Dengan tantangan yang dihadapi ASEAN, The International Labour Organization (ILO) telah memberikan beberapa rekomendasi terhadap ASEAN untuk menciptakan lapangan kerja yang lebih baik dan memastikan bahwa setiap negara dan sektor mendapatkan manfaat dari MEA. Untuk mengurangi kesenjangan keterampilan yang terjadi di ASEAN, diperlukan sistem edukasi yang lebih tinggi agar dapat merespon terhadap permintaan industri dan menjalin relasi dengan mitra-mitra sosial seperti pemerintah, pengusaha perdagangan, dan serikat buruh.

ILO merekomendasikan bahwa adanya reformasi struktural Technical and Vocational Education and Training (TVET) dengan tujuan menyediakan keterampilan yang sesuai dengan permintaan domestik dan internasional. Dengan adanya kualifikasi nasional yang sesuai dengan standar ASEAN, pekerja domestik dapat peluang lebih besar untuk bekerja di negara-negara ASEAN lainnya. ASEAN Qualifications Reference Framework menjadi pedoman bagi negara-negara ASEAN mengenai edukasi yang mereka perlu berikan untuk meningkatkan keterampilan dan menjamin kualitas dari pendidikan yang ada.

ILO menekankan pentingnya edukasi untuk mengurangi kesenjangan keterampilan dalam negara-negara ASEAN. Edukasi juga dapat berbentuk KPBU. Sebagai contoh, di India beberapa sekolah di daerah terbelakang menjadi tanggung jawab sektor swasta kepada pemerintah. KPBU ini dilakukan untuk menjamin akses masyarakat kepada edukasi di daerah terbelakang. Murid-murid yang terdaftar di sekolah tersebut hanya perlu membayar sebagian dari biaya studi dan sisanya akan ditanggung oleh pemerintah. ${ }^{26} \mathrm{KPBU}$ berbentuk edukasi ini menjamin akses masyarakat terhadap edukasi yang pada akhirnya mengurangi kesenjangan keterampilan. Edukasi yang menjadi kunci dari kesenjangan keterampilan dapat dicapai dengan adanya KPBU.

Pembahasan dan manfaat dari triangulasi KPBU ini dapat dilihat dari 2 sektor: domestik dan internasional. Secara domestik, diperlukan sistem pelatihan keterampilan yang sesuai dengan permintaan pasar karena dengan ini, kesenjangan keterampilan akan berkurang. Dengan berjalannya KPBU, pemerintah akan mencari sektor swasta yang memiliki keterampilan yang sesuai dengan permintaan mereka. Sektor swasta didorong untuk memiliki tingkat keterampilan yang sesuai dengan permintaan pemerintah agar mereka mendapatkan proyek tersebut yang adalah sumber pendapatan

\footnotetext{
${ }^{25}$ Aring, Monica. ASEAN Economic Community 2015: Enhancing Competitiveness and Employability through Skill Development. Working paper. Bangkok: International Labour Organization, 2015.

${ }^{26}$ Tilak, J. B. Public Private Partnership in Education (pp. 10-11, Publication no. 3/2016). Head Foundation. 10-11
} 
sektor swasta dalam triangulasi KPBU. Kebutuhan ini bersifat dua arah, dimana pemerintah membutuhkan sektor swasta yang memiliki tingkat keterampilan yang sesuai dan sektor swasta juga memerlukan proyek dari pemerintah untuk pendapatan.

ASEAN dalam triangulasi KPBU ini berperan dalam menciptakan framework yang disebut sebagai ASEAN Qualifications Reference Framework yang mengatur edukasi dan sistem pelatihan untuk pekerja memiliki standar yang sama. ${ }^{27}$ Dengan standar ini, seluruh pekerja di negara ASEAN dapat dengan bebas memilih untuk bekerja di dalam negeri atau di luar negeri karena sudah mencapai standarisasi regional.

Secara internasional, pekerja dari seluruh negara ASEAN akan merasakan manfaat dari triangulasi KPBU antara pemerintah, sektor swasta, dan ASEAN. Sektor swasta dapat dengan mudah mendapatkan proyek dari pemerintah domestik maupun luar negeri. Para pekerja yang sudah mendapatkan pelatihan dan edukasi dengan standar ASEAN dapat dengan mudah mencari pekerjaan di negara-negara ASEAN lainnya. Pemerintah negara ASEAN juga tidak lagi meragukan kualitas keterampilan tenaga kerja asing karena seluruh negara ASEAN memiliki standar yang sama. ASEAN dapat menjalani mekanisme KPBU yang baru yaitu sektor-sektor swasta dari negara masing-masing dapat bekerja sama dengan pemerintah untuk menjalankan PPP dibawah pengawasan ASEAN. Dengan mekanisme yang baru ini, kerja sama ASEAN secara regional dalam segi ekonomi dapat diperkuat dengan adanya KPBU dengan skala yang lebih besar. KPBU yang pada awalnya hanya dapat mencakup negara secara domestik sekarang dapat mencakup kerja sama regional antar-negara anggota ASEAN.

\section{Kesimpulan dan saran}

Memasuki era liberalisasi ekonomi, ASEAN menghadapi permasalahan yang sangat berdampak terhadap pertumbuhan ekonominya, yaitu ketimpangan keterampilan. Ketimpangan keterampilan ini sangat mengancam bagi pertumbuhan ekonomi karena ketidaksesuaian permintaan perusahaan dan penawaran keterampilan yang berada dalam masyarakat itu sendiri. Penawaran keterampilan di ASEAN sebagian besar berada di sektor agrikultur dikarenakan budaya yang masih kuat dalam hal tersebut.

Namun, permintaaan keterampilan dari perusahaan bergantung kepada sektor industri, spesifiknya, dalam bidang STEM. Permintaan keterampilan yang tinggi ini disebabkan adanya kemajuan era digitalisasi. Masyarakat yang tidak dapat menyesuaikan dengan permintaan keterampilan ini memiliki potensi besar menjadi pengangguran nantinya. Sebagai solusi, KPBU dapat membantu sektor pendidikan untuk meningkatkan kesadaran masyarakat ASEAN bahwa STEM dan soft skill adalah hal yang penting untuk dipelajari.

KPBU yang biasanya bersifat dua arah antara pemerintah dan sektor swasta akan menjadi lebih efektif ketika melibatkan pihak ke-3 yaitu ASEAN. KPBU ini bersifat tiga arah antara pemerintah, sektor swasta dan ASEAN, yang nantinya akan saling bekerja sama untuk meningkatkan pertumbuhan

\footnotetext{
${ }^{27}$ Ibid
} 
ekonomi di ASEAN. ASEAN dapat mendorong negara anggota untuk memiliki edukasi yang memadai dalam bidang STEM. Pemerintah dapat bekerja sama dengan ASEAN untuk memastikan bahwa edukasi TVET mengenai STEM ini berjalan dengan efektif. Sektor swasta dapat bertanggung jawab atas institusi edukasi. Dengan ini, triangulasi KPBU akan membantu negara anggota ASEAN untuk mencapai cetak ASEAN 2025 dan mengurangi adanya kesenjangan keterampilan.

Berdasarkan hasil penelitian dan analisis yang telah dilakukan, penulis merekomendasikan sejumlah saran untuk menanggulangi permasalahan yang ada dalam mekanisme KPBU sebagai berikut:

1. Mengubah dan mengarahkan kurikulum agar menekankan pentingnya STEM, dikarenakan ASEAN sedang memasuki Revolusi Industri 4.0 yang sarat akan bidang STEM, baik peminat maupun peluang pekerjaan yang sangat besar.

2. Meningkatkan koordinasi antara pemerintah, sektor swasta, institusi pendidikan, dan ASEAN. Koordinasi antara pemerintah dan ASEAN dibutuhkan agar ASEAN mengetahui kondisi terkini seperti permintaan pekerjaan tertinggi terkini sehingga ASEAN dapat menyediakan standardisasi dalam bentuk kerangka kerja untuk menyamaratakan kualitas pendidikan. Koordinasi antara sektor swasta dan institusi pendidikan diperlukan untuk kepentingan seperti memberikan pelatihan bagi pelajar dan pekerja, agar pendidikan yang didapat sesuai dengan kebutuhan industri.

3. Memberikan insentif dan perhatian lebih kepada program pelatihan keterampilan yang diadakan oleh sektor swasta. Program-program keterampilan ini seharusnya mendapatkan lebih banyak perhatian karena dapat membantu mengembangkan soft skill bagi warga negara yang belum dapat menempuh pendidikan formal.

4. Menghimbau sektor swasta untuk mempertimbangkan untuk memberikan pekerjaan paruh waktu atau kesempatan magang kepada para pekerja ketika tidak dapat mempekerjakan secara penuh waktu. Hal ini berguna untuk mempertahankan produktivitas perusahaan dan juga para pekerja. 


\section{Daftar Pustaka}

"Human Capital Outlook: Association of Southeast Asian Nations (ASEAN)." World Economic Forum, http://www3.weforum.org/docs/WEF_ASEAN_HumanCapitalOutlook.pdf. (Diakses 30 Juli 2019).

"Managing Skills Challenges in ASEAN-5." J.P.Morgan. https://www.jpmorganchase.com/corporate/Corporate-Responsibility/document/ASEAN5executive-summary-final.pdf (Diakses 1 Agustus 2019).

"National Public-Private Partnership Frameworks in ASEAN Member Countries." ERIA. N.d. http://www.eria.org/PPP\%20in\%20ASEAN_Full\%20Report_2015.pdf. (Diakses 30 Juli 2019).

"What are Public Private Partnerships?" World Bank Group. 2 Juni 2018. https://ppp.worldbank.org/public-private-partnership/overview/what-are-public-privatepartnerships (Diakses 25 Juli 2019).

Aring, Monica. 2015. ASEAN Economic Community 2015: Enhancing Competitiveness and Employability through Skill Development. Working paper. (Bangkok: International Labour Organization).

Aring, Monika. "ASEAN Economic Community 2015: Enhancing Competitiveness and Employability Through Skill Development.” International Labour Organization. February 2015. https://www.ilo.org/wcmsp5/groups/public/---asia/---robangkok/documents/publication/wcms_344796.pdf. (Diakses 29 Juli 2019).

ASEAN. “About ASEAN.” https://asean.org/asean/about-asean/. (diakses 23 Juli 2019).

ASEAN. "ASEAN Framework Agreement on Services.” N.d. https://asean.org/?static_post=aseanframework-agreement-on-services. (Diakses 23 Juli 2019).

\section{ASEAN. “ASEAN PUBLIC-PRIVATE PARTNERSHIP REGIONAL FRAMEWORK FOR} TECHNOLOGY DEVELOPMENT IN THE FOOD, AGRICULTURE AND FORESTRY (FAF) SECTORS.” N.d. https://asean.org/storage/2012/05/18.-ASEAN-PPP-FrameworkFAF.pdf (Diakses 30 Juli 2019).

ASEAN. 2015. ASEAN Economic Community Blueprint 2025. (Jakarta: ASEAN Secretariat) F., Zen dan M. Regan (eds) (2014). "Financing ASEAN Connectivity." ERIA Research Project Report No. 15. http://www.eria.org/publications/research_project_reports/FY2013/No.15.html (Diakses 29 Juli 2019).

Kementerian Luar Negeri Republik Indonesia. "Masyarakat Ekonomi ASEAN (MEA)." 1 Agustus 2019. https://kemlu.go.id/portal/id/read/113/halaman_list_lainnya/masyarakat-ekonomi-aseanmea, (Diakses 23 Juli 2019).

Minghui, Shen. 2018. "Evaluation of Regional Economic Integration in East Asia." dalam Asian Economic Integration in an Era of Global Uncertainty. Shiro Amstrong dan Tom Westland (ed.). Hlm. 259 - 292. (Australia: ANU Press). 
Pangestu, Mari dan Shiro Armstrong. 2018. "Asian Economic Integration: The State of Play," dalam Asian Economic Integration in an Era of Global Uncertainty, Shiro Amstrong dan Tom Westland (ed.). Hlm. 15 - 62. (Australia: ANU Press).

Schwab, Klaus. “The Global Competitiveness Report 2014-2015.” World Economic Forum. http://www3.weforum.org/docs/WEF_GlobalCompetitivenessReport_2014-15.pdf (Diakses 29 Juli 2019).

Tilak, J. B. 2016. Public Private Partnership in Education (pp. 10-11, Publication no. 3/2016). Head Foundation.

Vineles, Phidel. "Enhancing ASEAN's Competitiveness: The Skills Challenge.” RSIS. 12 Januari 2018. https://www.rsis.edu.sg/wp-content/uploads/2018/01/CO18006.pdf. (Diakses 29 Juli 2019). 